\title{
As produções de si com(o) outro: aprendizagem e produção de alteridades
}

\author{
Álamo Pimentel*
}

\section{Resumo}

O presente ensaio procura destacar a relevância das conversações entre antropologia e educação, com especial ênfase nas noções de aprendizagem e produção de alteridades. Trata-se de um estudo teórico que opera análises de discursos em três conferências realizadas por antropólogos que estudam etnicidade. O objetivo é apresentar como a produção teórica sobre a etnicidade também é produtora de outras formas de compreensão da aprendizagem e da alteridade. Procura-se salientar a importância do aprender nas diferentes circunstâncias dos encontros interculturais e, com isto, aprofundar reflexões sobre abordagens multiculturais dos processos educativos no âmbito da formação de professores.

Palavras chave: Antropologia. Formação de professores e etnicidade.

* Doutor pela Universidade Federal do Rio Grande do Sul. Professor do Centro de Formação em Ciências Humanas e Sociais da Universidade Federal do Sul da Bahia (UFSB). 


\section{Introdução}

A entrada do Brasil no milênio atual introduziu, na agenda de debates sobre educação e formação de professores, uma série de temáticas com efetivo impacto no âmbito das políticas públicas, da produção de conhecimento e na atuação de movimentos sociais que reivindicam transformações significativas nas configurações vigentes dos processos educacionais em contextos escolares e não escolares. Destacam-se, neste ensaio, aspectos referentes à etnicidade e educação, com especial ênfase na busca de aproximações teóricas entre a antropologia e a educação, sobretudo no que diz respeito às formas como o discurso antropológico acerca da etnicidade produz formas de compreensão da aprendizagem nos processos de produção de alteridade circunscritos à constituição de diferentes grupos étnicos.

Inicialmente, aponto alguns aspectos que perpassam as aproximações e distanciamentos entre a antropologia e a educação, a fim de destacar a importância de uma visão interdisciplinar mais profunda sobre questões relacionadas à educação e cultura nos processos de formação de professores. Em seguida, detenho-me na análise de alguns discursos sobre a etnicidade no campo da antropologia. A partir de uma perspectiva pós-colonial, procuro destacar que outras experimentações teóricas da aprendizagem, capazes de romper com as visões psicocêntricas, ou mesmo sociocêntricas, do aprender, podem inspirar transformações no trato com questões educacionais e questões de etnicidade rumo a uma abordagem multicultural dos processos educativos.

\section{Antropologia, educação e formação de professores}

No que se refere à formação de professores, parto do pressuposto de que, apesar das inúmeras transformações culturais em escalas locais e globais, as relações entre a educação, escolar no sentido mais restrito, e a cultura, no sentido mais amplo do termo, ainda são marcadas por inúmeros conflitos, sobretudo pelo caráter monocultural e homogeneizador da educação escolarizada. Não é demais lembrar que "as relações entre cotidiano escolar e cultura(s) ainda constituem uma perspectiva somente anunciada em alguns cursos de formação inicial e/ou continuada de educadores/as e pouco trabalhada em nossas escolas" (CANDAU, 2011, p. 35). Diante de tal afirmação, procuro destacar que os aspectos referentes à compreensão dos processos constitutivos da etnicidade, tanto no que se refere às lutas sociais pela produção e reconhecimento de outras formas de autodenominações étnicas como no âmbito 
da produção teórica em torno destas questões, passam ao largo dos processos de formação de professores e, em alguma medida, acrescentam complexidade aos desafios contemporâneos para a lida com esta temática no cotidiano das instituições educacionais.

Processos de homogeneização cultural atravessam os muros das escolas e produzem formas de controles e segregação identitários na construção de currículos, na formação de professores e nas relações de ensino aprendizagem, como bem nos mostra Michael Apple (2000). Questionar as bases epistemológicas e societais em que tais processos se consolidam pressupõe: colocar as formas de produção do "outro" de um ponto de vista político porque pedagógico. Neste sentido, além de apontar questionamentos sobre a institucionalização de paradigmas monoculturais acerca dos modelos de formação de professores em que a alteridade se vê reificada pela homogeneização das políticas de identidades presentes na escola, sugiro também o incontornável desafio da inscrição de políticas de agência que sejam capazes de articular lutas políticas no trabalho pedagógico a partir do compromisso crítico com a convivência multicultural, conforme indica Peter McLaren (2000). Neste sentido, busco conduzir uma reflexão pautada pelas contribuições da pedagogia crítica na emergência de um pensamento pós-colonial no campo da educação.

Podem-se constatar algumas tensões nos processos de formação de professores no Brasil que, em alguma medida, indicam a relevância de uma compreensão mais alargada das interfaces entre educação e cultura no que se refere às questões de etnicidade. Procuro destacar duas dessas tensões, a título de ampliar as bases em que tento desenvolver os argumentos apresentados mais adiante. A primeira delas remete às distorções conceituais dos discursos sobre raça e etnia que circulam em diversos contextos sociais brasileiros, inclusive na escola e nos diferentes espaços de formação de professores. Apesar de uma significativa distância histórica do modelo colonial que instituiu a formação cultural do nosso país, é possível identificar formas de colonialismo interno, conforme nos lembra Mary Louise Pratt (1999), que produzem o entrechoque das formas discursivas amplamente generalizadas sobre o outro que constituem os matizes históricos e geográficos das diferenças interétnicas no Brasil, e as atuações de grupos que questionam e se rebelam contra tais discursividades, buscando compor outras referências discursivas de pertencimento cultural na contemporaneidade. Somos herdeiros e produtores de discursos raciais ainda marcados pelos efeitos da dominação colonial, que gerou formas extremas de compreensão das diferenças étnico-raciais na formação cultural do nosso país:

Esse efeito do discurso racial foi embotado pelas ciências durante o curso da dominação colonial do século XIX. A hierarquização das raças embora comumente seja referida como uma ideia restrita a um período histórico específico tem, sem dúvida, efeitos que perduram ainda na 
sociedade contemporânea. Isto inclui obviamente as instituições escolares, através da qual uma significativa parcela dos indivíduos assimila saberes e valores [...]. (BRANDÃO; SILVA, 2008, p. 422).

Da inferiorização intelectual que produziu a interdição das diferenças culturais, e mesmo da presença física, de povos indígenas e afrodescendentes dos sistemas educacionais vigentes no século XIX aos discursos sobre a democracia racial que sustentaram as teorias e as políticas de integração dos diferentes povos do Brasil no século XX, as escolas e as instituições de formação de professores se veem atravessadas em seus cotidianos por imagens distorcidas do outro, não europeu, não branco. Estas imagens são produzidas no interior das relações de poder que, conforme Tomaz Tadeu da Silva (2000), disputam a fixação da identidade e da diferença a partir de mecanismos de naturalização e pelos essencialismos que preenchem os parâmetros institucionais de reconhecimento prévio do outro. Identidade e diferença operam discursos cotidianos escolares que produzem conflitos entre visões estabelecidas dos outros e silenciam ou combatem outras formas de autodenominações de si-com-osoutros nas lutas sociais que também estão presentes na escola.

Nesse nível de tensão, a formação de professores é perpassada pelos preconceitos cotidianos que fazem falar (ou mesmo calar) visões amplamente deformadas sobre o outro não enquadrado nos padrões culturais vigentes nas mais distintas regiões do país. Por outro lado, a produção teórica sobre a cultura e, de forma mais específica, sobre a etnicidade, predominou na constituição de um campo temático da antropologia social e cultural, área do conhecimento das ciências humanas que, por razões também históricas, foi apartada da educação. A este respeito, Amurabi Oliveira (2012) apresenta-nos algumas reflexões que indicam, de forma precisa, as tensões que transpassam as relações entre antropologia e educação. Este autor nos faz compreender que a separação da antropologia e da educação está presente nos cenários institucionais que historicamente constituíram os principais espaços de formação de professores no Brasil. Apesar do esforço recente de algumas instituições voltadas para a formação de educadores, ao adotarem a Antropologia da Educação (ou componentes interdisciplinares com outras denominações, mas com propósitos congêneres a esse campo do saber) como componente curricular dos seus cursos, tanto nos cursos de Pedagogia quanto nos cursos de Ciências Sociais, este componente curricular inexiste ou é oferecido de forma residual, com pequena carga horária e limitado escopo de discussões teóricas. A partir das análises deste autor, destaco três níveis de ressonância de conflitos provocados pela separação da produção intelectual no âmbito da antropologia e da educação, que merecem alguma ênfase para as análises que faço a seguir: a) ressonâncias epistemológicas, b) ressonâncias pedagógicas e c) ressonâncias políticas. 
Do ponto de vista epistemológico, as teorias educacionais vigentes no Brasil estabeleceram suas bases conceituais entre as psicologias do comportamento e da cognição, enfatizando o indivíduo a partir de teorias do sujeito amplamente generalizadoras de uma "certa" versão do sujeito da aprendizagem. No que diz respeito às análises educacionais de abrangência sociológica, foram produzidas teorias com ambições macroconceituais que focalizam muito mais as estruturas sociais determinantes das condições de aprender nos processos educacionais escolarizados em termos genéricos, fixando os mesmos conceitos (do tipo fracasso e sucesso escolar) para situações variadas de conflitos de aprendizagem e eliminando de suas análises outras formas de organização da sociedade que se fazem cotidianamente dentro e fora das escolas. No que se refere à produção teórica sobre a(s) cultura(s), esta ficou concentrada no âmbito da antropologia e, ao longo dos anos de formação desse campo de conhecimento, passou por inúmeras transformações, produziu enfoques muito diferenciados acerca do que é a cultura como um fenômeno que transpassa as experiências vividas pelas pessoas em diferentes grupos sociais, bem como um conceito de base para a constituição epistemológica desta área do conhecimento.

Importante ressaltar que, no início do século XX, a constituição do pensamento social no campo da educação recorreu à antropologia física, à psicologia e à sociologia como fundamentos do discurso cientificista de "conversão" do outro arcaico, rústico, ao estado de civilizado, conforme aponta Marcos Cezar Freitas (2005). Ainda segundo o autor, estas ciências, sobretudo a psicologia, operaram uma suspensão disciplinar da pedagogia, atribuindo aos seus fundamentos epistemológicos superioridade conceitual capaz de definir, controlar e mesmo moldar o vasto repertório das práticas pedagógicas presentes na construção do Brasil moderno.

As críticas aos usos da antropologia física no alvorecer no século XX produziram um drástico distanciamento do campo educacional com esta área de conhecimento, apesar das inúmeras transformações pelas quais a antropologia brasileira tem passado, sobretudo no que diz respeito aos avanços da antropologia social (e cultural), que se distingue, profundamente, da abordagem biologizante da antropologia física presente nos métodos antropométricos utilizados nas escolas brasileiras no século passado (FREITAS, 2005). As transformações epistemológicas do campo educacional não se fizeram em regime de dialogicidade com as transformações do campo antropológico, e só recentemente, conforme mencionado anteriormente, é que o diálogo interdisciplinar entre educação e antropologia passou a buscar novas bases de interação.

Tanto da parte da educação quanto da parte da antropologia, as formas de segregação institucional das teorias sociais que perpassam as relações entre indivíduos, cultura e sociedade 
produzem desafios que remetem à busca de aproximações interdisciplinares que sejam capazes de gerar novos horizontes na produção do conhecimento relevante para a formação de professores. A este respeito, destaco as produções desenvolvidas por Peter Maclaren (1992), Gilmar Rocha e Sandra Pereira Tosta (2009), Tânia Dauster (2012), Clarice Cohn (2009). A produção da alteridade nas relações de ensino-aprendizagem é uma das marcas transversais ao pensamento destes autores. Suas produções buscam reduzir desníveis epistemológicos entre a educação e a antropologia a partir de um pensamento interdisciplinar em que diferenças conceituais tornam-se geradoras de novas sínteses teóricas em lugar de produzir hierarquias epistêmicas.

As ressonâncias epistemológicas afetam os aspectos pedagógicos na formação de professores. Um dos investimentos teóricos na política de produção de conhecimento da antropologia educacional é o questionamento da divisão epistemológica entre ensinar e aprender. As práticas de ensino que vicejam nas instituições voltadas para a formação de professores são marcadas por distinções radicais entre o ensino e a aprendizagem e, sobretudo, pela ênfase nos discursos institucionais que delimitam lugares e papéis que diferenciam aquele que ensina daquele que aprende. Em linhas gerais, aquele que ensina é portador do conhecimento institucionalmente válido para formar aquele que aprende, este último sempre anunciado como sujeito em vias de emancipação social a partir do seu adequado enquadramento no processo de escolarização. Professores são formados para produzirem outros processos de formação a partir dos marcos regulatórios de suas práticas de ensino, que definem papéis institucionais desde uma distribuição desigual do conhecimento válido no âmbito restrito dos espaços escolares. Por outro lado, a educação é uma área do conhecimento que contribui significativamente para a geração de outras formas de produzir conhecimento, uma vez que o trânsito da experiência de formação, assim como o trânsito das experiências de atuação como professor, é reconhecidamente multi-interdisciplinar.

A antropologia não produziu apenas teorias sobre a cultura, mas alterou significativamente atitudes na relação com o outro, à medida que aspectos como "o estranhamento etnográfico" e "a alteridade" operam agenciamentos de sentido que transformam não apenas a teoria, mas também as formas de fazer teoria (CAIAFA, 2007). Neste nível de ressonância, que chamo de pedagógica, destaco que a educação pode contribuir com a antropologia à medida que o conhecimento produzido para a formação de professores alarga horizontes de práticas interdisciplinares, gerando novas formas de produzir e pôr em circulação saberes os mais diversos. Ao mesmo tempo, penso que a atitude antropológica que orienta a busca pelo conhecimento, a partir daquilo que não é sabido sobre o outro, pode contribuir para a formação de professores. Sobretudo quando compreendemos que esta atitude 
antropológica só se torna possível à medida que são desnaturalizadas as formas preestabelecidas de reconhecimento mútuo, tanto da parte do antropólogo quanto da parte dos grupos sociais com os quais convive.

Por fim, as duas ressonâncias produzem efeitos em nível político. Isto porque, tanto no que diz respeito aos aspectos mais cotidianos das instituições educacionais, onde circulam preconceitos e visões de mundo excessivamente escolarizadas e normalizadoras dos outros, quanto no que diz respeito à segregação institucional das áreas de conhecimento que constituem a antropologia e a educação, as demandas por novos referenciais de formação, com ênfase, sobretudo, nas configurações multiculturais do mundo contemporâneo, geram novos desafios para a produção do conhecimento e a construção de processos de formação de professores que sejam capazes de enfrentá-los.

O que eu pretendo neste ensaio é compreender a aprendizagem e a produção da alteridade como práticas constitutivas dos processos de diferenciação das relações com os outros na composição dos discursos antropológicos sobre etnicidade. Identidade e diferença, aqui, aparecem como termos subjacentes em processos mais amplos que atravessam as relações do trabalho de campo e repercutem nos textos etnológicos que narram as experiências vividas pelos antropólogos com os seus outros e alteram significativamente suas formas de compreenderem a si mesmos, aos outros com os quais convivem e às teorias advindas destas experiências de convívio.

Nesse estudo teórico, tento explorar uma abordagem que "descreva e explique o processo de produção da identidade e da diferença" (SILVA, 2000, p. 99) no âmbito dos discursos sobre a etnicidade, a título de reconhecer os agenciamentos de sentido que operam os discursos sobre a negociação de presenças entre pessoas que pertencem a grupos sociais diferentes e, ao mesmo tempo, buscam constituir lugares de pertencimento fora da sentença (BHABHA, 1998, p.253), ou, ainda, compor entrelugares que instituam processos fronteiriços nos encontros e nas negociações de sentido para as experiências vividas na antropologia e na educação. Em outras palavras, tento romper com as sentenças disciplinares constitutivas das teorias da etnicidade para expor as suas enunciações e buscar aproximações discursivas com temas educacionais pertinentes às reflexões aqui propostas.

\section{Perspectivas antropológicas sobre etnicidade, aprendizagem e produção de}

\section{alteridades}

Os estudos de etnicidade têm destacado a importância dos processos de interação dos indivíduos na formação de grupos sociais e nas diferentes formas de denominação das identidades que colocam em destaque os atributos étnicos destes grupos. Isto pode ser observado nos trabalhos pioneiros de 
Darcy Ribeiro (1996), que abordam as interações na perspectiva do contato interétnico, realçando a emergência da aculturação como motor da integração entre as populações indígenas e a sociedade nacional. Outra proposta de abordagem indica que as variações culturais, que geram os processos de etnicidade, são descontínuas, e os processos de interação que lhes são subjacentes estão baseados em formas de organização social e construção de fronteiras culturais (BARTH, 2000). Em que pesem as diferenças teóricas entre tais formas de abordagem, o que ambas destacam, e desperta o interesse deste ensaio, é a ênfase no conceito de interação como pressuposto da produção de relações sociais e culturais entre os indivíduos e os grupos étnicos nos quais assumem lugar.

Procuro colocar ênfase nas contribuições dos estudos de etnicidade para a compreensão da aprendizagem e da produção de alteridade como fenômenos emergentes dos processos de circulação dos indivíduos no interior dos seus grupos de pertencimento, bem como em outras escalas de circulação social. Para isto, faço uma análise de três artigos que abordam questões de etnicidade em diferentes cenários sociais, mas que remetem a um ponto de vista teórico comum: os três textos destacam as interações como processos de produção de significados em diferentes formas de organização social do pertencimento étnico. Coloco em destaque o texto de José Maurício Arruti (2004), que aborda as etnogêneses indígenas no nordeste brasileiro sob a influência da igreja. Em seguida, destaco o texto de Fredrik Barth (2005), no qual o autor procura correlacionar os estudos de etnicidade ao conceito de cultura. Por fim, destaco aspectos do texto de Roberto Cardoso de Oliveira sobre os processos de etnização e construção de identidades entre imigrantes em diferentes circunstâncias de convivência com as suas "sociedades anfitriãs".

Os três artigos analisados foram produzidos em diferentes circunstâncias e buscam responder a diferentes questões, embora tenham em comum o fato de terem sido inicialmente apresentados como conferências para eventos acadêmicos. Além desse ponto convergente - serem objeto de trabalho em conferências -, outro fator que os aproxima é a orientação de Fredrik Barth (2000), que destaca, no seu famoso texto de introdução à coletânea intitulada Os grupos étnicos e suas fronteiras (1969), os processos de organização das interações entre as pessoas e a produção de fronteiras culturais como dimensões geradoras de distintivos étnicos. Tais artigos remetem à interação como processo gerador de diferentes formas de aprender a conviver com o outro. As distintas circunstâncias e escalas de convívio social com as diferenças étnicas produzem movimentos de organização e delimitação de fronteiras entre grupos sociais. Nesse sentido, lanço a seguinte questão: é possível compreender a aprendizagem e as produções da alteridade como formas de trânsito cultural a partir das aproximações discursivas entre Oliveira, Arruti e Barth? Considerando que os autores enfatizam configurações empíricas diferentes ao 
mesmo tempo em que remetem a construções teóricas com alguns "traços" aparentemente comuns, a questão lançada supõe problematizar os aspectos processuais das interações indicadas em seus textos como formas de "trânsito cultural". Em linhas gerais, as interações não se constroem a partir das diferenças imediatas das relações sociais em campo, tais interações emergem das condições de possibilidades que produzem as diferenciações entre os interlocutores nos mais distintos contextos em que se situam.

No que diz respeito à enunciação de cultura que orienta este ensaio, sigo a orientação de “[...] que a cultura deve ser constantemente gerada pelas experiências por meio das quais se dá o aprendizado [...]" (BARTH, 2005, p. 16). Ainda segundo o mesmo autor, a cultura é distribuída pelas pessoas em processos de interação e apresenta-se em estado de fluxo constante (BARTH, 2005). Com base nessa perspectiva, defino a aprendizagem como princípio de um processo instável de interação através do qual os indivíduos participam da circulação de práticas e saberes dos grupos sociais em que estão inseridos. À medida que interagem uns com os outros, os indivíduos contribuem para a geração de referências de identificação em que consolidam suas relações interpessoais. Tais referências se alteram conforme mudam os contextos de interação. Nesse sentido, proponho, ainda, que toda aprendizagem articula-se à produção de alteridade, ou seja, à medida que os indivíduos criam suas alternativas de acesso e circulação dentro dos seus próprios grupos (ou com outros grupos também) ocorrem, comumente, processos de produção e negociação social das condições de diferenciação e pertencimento a grupos sociais. Isto reivindica colocar em destaque os processos que geram situações de alteridade.

A alteridade não é tomada como um fundamento desde sempre estabelecido na constituição da antropologia. Aponto que se trata de um conceito problemático na constituição dos discursos antropológicos e proponho pensá-la não a partir daquilo que é, mas desde como é produzida em campo. Esta orientação acerca da produção de alteridade está inspirada, por sua vez, nas seguintes afirmações:

Ainda que - ou justamente porque - a alteridade, em si mesma, seja fundadora do empreendimento antropológico, ela costuma se apresentar como um suposto de suas análises, um objeto dado, mais do que algo sobre o qual se devia investir como problemática. No entanto, a etnografia das situações de contato, interação, guerra, comércio ou diálogo, enfim das situações de troca e mediação intersocietária e intercultural, nos permitem sugerir uma abordagem da alteridade também enquanto artefato, tanto cognitivo quanto social e material. Com isso a alteridade se nos apresentaria não só como evidência, mas também como objeto cujo processo de produção e negociação social devem ser tomados como problemáticos. (ARRUTI, 2004, p. 2).

Além de ser um processo em que os indivíduos produzem relações com os seus outros, a alteridade se configura, também, como artefato cultural, objeto de negociação com o qual os indivíduos 
aprendem a lidar com os saberes e práticas que identificam suas relações de pertencimento; aliás, todo o esforço do autor é construído em torno da interpretação do Toré como um código que orienta as interações entre os indígenas em processos de etnogêneses, os antropólogos e os missionários com as suas pedagogias de conversão indígena. Dessa maneira, aprendizagem e produção de alteridade constituem interfaces de um mesmo processo, a que denomino de "trânsito cultural". Suponho, conforme sugerem os estudos de etnicidade em relevo nestas análises, que praticar identificações sugere fazer caminhos e (des)caminhos, conforme propõe Roberto Cardoso de Oliveira (2000), e, ao mesmo tempo, supõe a construção de fronteiras culturais que "canalizam a vida social e implicam o controle de comportamento e de diferenças persistentes" (BARTH, 2000, p. 34). Caminhos e fronteiras geram configurações dos processos de circulação social entre os fluxos e as formas de controle culturais que expressam a vida social em comum. A esses fluxos e à produção dos limites defino como formas de trânsito cultural no âmbito deste ensaio.

Para melhor compreensão dos contributos de cada autor, faz-se necessário destacar, em termos gerais, as especificidades da abordagem teórica de cada um dos seus textos sobre a etnicidade. O que eu tento fazer é uma análise de discurso através da qual coloco em destaque alguns aspectos de diferenciação e, depois, indico dimensões enunciativas (BHABHA, 1998) em que realço aproximações entre os autores. Tomo de empréstimo a ideia de que um autor está em função de instauração de um campo discursivo (FOUCAULT, 2006, p. 46) que produz outros tempos de significação cultural e outros espaços narrativos (BHABHA, 1998, p. 248), considerando que as análises aqui propostas remetem a reflexões de fora da antropologia e se voltam para intelectuais de várias áreas envolvidos com as questões de etnicidade na educação. Não deixo de considerar que, em se tratando de artigos produzidos por antropólogos, tais obras não estão dissociadas das práticas de campo dos seus autores, o que sugere que "[...] eles demarcam a paisagem intelectual, diferenciam o campo do discurso [...]" (GEERTZ, 2009, p. 33). Para isto, destaco, de forma resumida, as diferenças de enunciações entre os autores a partir de três critérios: a) identificação das condições de autoria (quem escreve, quando escreve, para quem escreve e de que lugar se anuncia); b) distinção das suas ênfases temáticas; c) exposição das suas configurações empíricas. Cada texto é portador de uma assinatura, que indica a sua identidade autoral, ainda conforme as orientações de Clifford Geertz (2009), ao mesmo tempo suas ênfases temáticas distinguem suas abordagens conceituais no campo da etnicidade, e suas configurações empíricas, além de apresentar grupos étnicos específicos, apresentam estes grupos em situações contextuais distintas. 
Parto do pressuposto de que estas diferenças de enunciação supõem diferenças de posicionamentos discursivos dentro do debate sobre etnicidade. Contudo, entrevejo também alguns agenciamentos de sentido nas interlocuções entre os autores. Compreendo tais agenciamentos de sentido como operações de cofuncionamento que emergem das simpatias (CAIAFA, 2007) nas composições discursivas que aproximam os autores. Tais composições estão nos relevos dos seus textos, principalmente pela influência de Fredrik Barth nos estudos de etnicidade no final dos anos 1960 do século passado. Após uma breve exposição do desenvolvimento das diferenças entre cada texto, apresento um quadro geral de análise, a título de estabelecer correlações teóricas e empíricas para compreender as conexões entre os conceitos de aprendizagem, produção de alteridade e trânsito cultural ou, em outras palavras, indico elementos que apontam para a partilha de um "campo discursivo" entre os autores.

\section{As etnogêneses no nordeste e as "produções de si com os outros em casa"}

O artigo de José Maurício Arruti é uma conferência dirigida aos participantes do VIII Congresso Luso-Afro-Brasileiro de Ciências Sociais, realizado em Coimbra, Portugal, no ano de 2004. $\mathrm{O}$ autor se posiciona para um público especialista e levanta hipóteses e questões que afirma serem relevantes para a compreensão da presença de agentes externos aos grupos indígenas nos processos de etnogêneses. Ao final do texto, na cabeça do primeiro parágrafo das conclusões, encontra-se a seguinte afirmação:

Aos antropólogos interessados nos grupos indígenas da região, o estudo do papel da igreja nas etnogêneses não parece ter despertado maior interesse provavelmente porque isso está relacionado ao privilégio dado a um outro campo de interações dessas etnogêneses: o Estado (pensado tanto como tutor, quanto como fonte de recursos e garantidor de direitos). (ARRUTI, 2004, p. 32).

Tal afirmação reforça a mensagem enviada aos antropólogos com relação às lacunas das reflexões sobre o papel da igreja na abordagem das etnogêneses indígenas no nordeste Brasileiro. O texto é direcionado aos profissionais que atuam diretamente com as questões indígenas no Brasil.

No que diz respeito às etnogêneses, o interesse de Arruti (2004) é colocar em destaque a participação de agentes não indígenas, sobretudo missionários da igreja católica e antropólogos, no processo de autoatribuição do rótulo de índios por grupos que antes eram reconhecidos genericamente como sertanejos. A base material de suas argumentações resulta do trabalho de campo realizado para a elaboração de sua tese de doutoramento. Além de destacar discursos de agentes missionários, indígenas 
e cenas das suas observações de campo, o autor coloca ênfase em documentos que indicam as diferentes genealogias das etnogêneses do povo Xocó no Sertão Sergipano. O texto faz um esboço histórico destas etnogêneses.

Ao longo do seu texto, somos conduzidos às etapas distintas dos processos de conversão que tiveram como protagonistas os agentes missionários e os Xocó sergipanos. Os desdobramentos de suas análises expõem configurações empíricas com as quais somos levados a compreender as produções de si com os outros em casa, ou seja, os cenários dos Sertões Sergipanos servem de paisagem para, segundo as palavras do próprio autor, a instauração de "uma espécie de complementaridade entre as ideias de conversão à ‘palavra' dos pobres e a de ‘assunção’ étnica” (ARRUTI, 2004, p. 31), na qual o Toré passou a se constituir como um código de conversão, um artefato de alteridade. Dentro de casa, diferentes agentes cumpriram o papel de resgatar a indianidade através de ações pedagogicamente voltadas para a conversão de sertanejos à condição de pertencimento indígena. O que temos em termos de configuração empírica são as diferentes expressões da etnogênese como processo de geração de pertencimento étnico através das reelaborações práticas do Toré.

\section{Etnicidade e cultura sob a perspectiva das produções de si "longe de casa"}

O texto sob a assinatura de Fredrik Barth foi apresentado originalmente no ano de 1995 na conferência Rethinking Culture (Repensando a Cultura), na Universidade de Harvard. A versão analisada é uma tradução de Paulo Gabriel Hilu da Rocha Pinto publicada na revista Antropolítica (número 19) no ano de 2005. Nesse texto, o autor, que também se apresenta como professor de antropologia da Universidade de Oslo (Noruega) e na Boston University (EUA), retoma e revê as implicações do seu conceito de etnicidade, formulado no ano de 1969 em texto de introdução a uma obra em que vários autores trabalham, desde diferentes abordagens antropológicas, com o tema da etnicidade.

Logo no início da sua apresentação, o autor diz o seguinte: "Em 1969, afirmei que a etnicidade representa a organização social de diferenças culturais. Desse modo, este conceito levanta questões sobre a constituição daquilo que chamamos de cultura, mas somente em relação à sua base" (BARTH, 2005, p. 16). A sua ênfase temática recai sob a etnicidade como base ordenadora das relações sociais, bem como condição de interação em diferentes contextos de convívio social. 
O autor expõe exemplos de paquistaneses da etnia pathan que vivem na Noruega. A condição de distância geográfica altera significativamente os estatutos de etnicidade pathan, uma vez que, segundo o próprio autor, “[...] ser pathan no Paquistão é claramente ter uma identidade étnica distinta [...]" (BARTH, 2005, p. 19) e, ao estar na Noruega, tem que produzir novas referências na relação com a cultura local, bem como, ao mesmo tempo, criar formas de estabelecer outros limites culturais com os noruegueses, limites que se diferenciam, sobretudo, pelas condições de gênero e etária entre os pathan que vivem na Noruega. Importante destacar que, além de aprender novas práticas culturais, o grupo também produz formas de controle, silenciamento e apagamento de experiências. Um dos exemplos dado pelo autor para contornar os conflitos desta alteridade longe de casa é o seguinte: "Algumas meninas, nascidas na Noruega e fluentes em norueguês e na cultura dominante, são mandadas para 'casa' no Paquistão, [...] com uma passagem de ida, para descobrir, ao chegar, que não tem permissão de voltar [...]" (BARTH, 2005, p. 24). O autor quer nos mostrar que a cultura, além de estar em permanente fluxo, também está sob controle, ou seja, é importante levar em consideração as diferentes formas de agenciamento político que atuam sobre a cultura e os processos de etnicidade contemporâneos para compreender conflitos e buscar novas formas de negociação intercultural. Produzir-se com os outros longe de casa significa percorrer distâncias simbólicas na construção das fronteiras que delimitam os novos lugares de pertencimento, mas também exige, às vezes, recorrer às distâncias geográficas necessárias à manutenção das fronteiras.

\section{Etnização e produção de si "na casa dos outros"}

O texto de Roberto Cardoso de Oliveira, a exemplo dos outros artigos, também foi organizado para ser uma conferência apresentada durante o XXIII Encontro Anual da Anpocs, no ano de 1999. Posteriormente, o texto foi publicado na Revista Brasileira de Ciências Sociais (volume 15, $\mathrm{n}^{\circ} 42$ ) de fevereiro do ano de 2000. Neste artigo, o autor refere-se à comunidade de antropólogos, porém destaca, inicialmente, que o tema de que irá tratar "[...] deslizou sobre as demais disciplinas irmãs[...]" (OLIVEIRA, 2000, p. 8). Neste texto, a estratégia adotada para a definição do título transforma a palavra descaminhos em uma palavra-imagem - (des)caminhos - que, com a inscrição do sinal dos parênteses, expressa a direção do discurso para uma abordagem das ambiguidades da identidade naqueles processos que o autor irá identificar como etnização.

Roberto Cardoso de Oliveira indica a etnização como um processo que recorre à identificação e articulação entre identidades étnicas e nacionais em diferentes contextos de convívios entre imigrantes. 
O autor utiliza configurações empíricas de outros antropólogos sobre a condição de imigrante de brasileiros em contexto estadunidense, assim como destaca exemplos de suas próprias experiências em contextos catalães e nas fronteiras entre o Brasil e outros países da América do Sul.

A partir do seu discurso, somos conduzidos à reflexão sobre as produções de si em sociedades anfitriãs, ou, de maneira mais alegórica, ao reconhecimento dos processos de alteridade deflagrados quando nos localizamos nas casas dos outros. A intenção do autor é chamar a atenção da comunidade de antropólogos para a importância das pesquisas contemporâneas sobre a identidade, a partir do reconhecimento de que as diferenciações de contextos produzem ambiguidades, mas, ao mesmo tempo, geram limites culturais em que os indivíduos e grupos sociais buscam a valorização de suas identidades étnicas ou nacionais, reivindicam o respeito às diferenças e assumem posturas éticas na exigência de consideração. Neste sentido, o cenário que se coloca ao longo do texto, de sociedade anfitriã, é aquele que melhor traduz o duplo sentido (nacional e étnico) que atravessa as identidades contemporâneas, isto porque a condição de imigrante sugere não apenas estar longe de casa, mas também estar na casa dos outros.

\section{Recorrências discursivas e agenciamentos de sentido}

As diferenças temporais e locais dos textos analisados indicam as especificidades das identidades autorais que os assinam, as ênfases temáticas distintas dentro dos estudos de etnicidade e, sobretudo, os diferentes destaques dados às configurações empíricas, que, em sentido muito amplo, conforme a orientação de análise adotada neste ensaio, focalizam aspectos "situacionais" em que proximidade e distância sugerem condições de possibilidades para a produção da alteridade e deflagração dos processos interacionais com as suas aprendizagens subjacentes.

Os textos possuem em comum o fato de terem sido conferências dirigidas às comunidades de especialistas no tema, sobretudo antropólogos, seus discursos recorrem a referências anteriores que remetem ao texto de 1969 de Fredrik Barth, o que indica tal texto como um importante "instaurador de discursividade", conforme sugere Michel Foucault (2006) e, ao mesmo tempo, favorece um agenciamento de sentido provocador de reinscrições e negociações conceituais legitimadoras de outras formas de "agência como narrativa do discurso histórico" (BHABHA, 1998, p. 266). As conferências remetem a diferentes momentos da produção teórica nos estudos de etnicidade, estabelecem rupturas, mas, ao mesmo tempo, recorrem à noção de interação que está presente nos enunciados da organização 
social e da produção de fronteiras, que constituem as bases da teoria da etnicidade no pensamento precursor de Fredrik Barth.

O quadro de análise apresentado a seguir expõe de forma mais sistemática as correlações dos aspectos distintivos e complementares entre as dimensões discursivas dos textos colocadas em relevo neste ensaio. As colunas das extremidades (as duas primeiras e a última no sentido esquerda/direita) destacam as diferenças discursivas do texto (suas identidades autorais, suas ênfases temáticas e suas configurações empíricas). As duas colunas centrais (terceira e quarta no sentido esquerda/direita) destacam os principais eixos de enunciação nas quais ocorrem recorrências discursivas e agenciamentos de sentido. Observe-se que a coluna correspondente às interfaces conceituais apresenta um desdobramento interno, no qual as recorrências ao conceito de "interação" estão indicadas, e o desdobramento deste conceito segundo as noções centrais de cada texto especificamente. Isto sugere que a recorrência discursiva é geradora de interfaces de enunciações em que se operam agenciamentos de sentidos entre os textos. A coluna seguinte, que indica as implicações teóricas, aponta para as principais propostas a que chegam os autores.

Quadro 1 - Quadro Geral de Análise: articulações entre os conceitos de aprendizagem e produção da alteridade nos estudos de etnicidade

\begin{tabular}{|c|c|c|c|c|c|}
\hline $\begin{array}{l}\text { Identidades } \\
\text { Autorais }\end{array}$ & Ênfases Temáticas & \multicolumn{2}{|c|}{ Interfaces Conceituais } & $\begin{array}{l}\text { Implicações } \\
\text { Teóricas } \\
\text { Analisadas }\end{array}$ & $\begin{array}{l}\text { Configurações } \\
\text { Empíricas }\end{array}$ \\
\hline \multirow{2}{*}{$\begin{array}{l}\text { José Maurício } \\
\text { Arruti } \\
\text { (historiador e } \\
\text { antropólogo) }\end{array}$} & \multirow{2}{*}{$\begin{array}{l}\text { Etnogêneses no } \\
\text { nordeste e produção da } \\
\text { alteridade }\end{array}$} & \multirow[b]{2}{*}{ Interação } & Conversão & \multirow[b]{2}{*}{$\begin{array}{l}\text { Transformação do } \\
\text { Toré em código }\end{array}$} & \multirow[b]{2}{*}{ Grupo Xocó } \\
\hline & & & Alteridade & & \\
\hline \multirow{2}{*}{$\begin{array}{l}\text { Fredrik Barth } \\
\text { (antropólogo) }\end{array}$} & \multirow{2}{*}{$\begin{array}{l}\text { Etnicidade, cultura } \\
\text { e alteridade }\end{array}$} & \multirow{2}{*}{ Interação } & Aprendizagem & \multirow{2}{*}{$\begin{array}{l}\text { Distribuição da } \\
\text { cultura através } \\
\text { da experiência }\end{array}$} & \multirow{2}{*}{$\begin{array}{l}\text { Grupos Pathan na } \\
\text { Noruega }\end{array}$} \\
\hline & & & Alteridade & & \\
\hline \multirow[b]{2}{*}{$\begin{array}{c}\text { Roberto Cardoso } \\
\text { de Oliveira } \\
\text { (filósofo e } \\
\text { antropólogo) }\end{array}$} & \multirow[b]{2}{*}{$\begin{array}{l}\text { Etnização, imigração } \\
\text { e alteridade em } \\
\text { sociedades anfritiãs }\end{array}$} & \multirow[b]{2}{*}{ Interação } & Identificação & \multirow[b]{2}{*}{$\begin{array}{l}\text { Tradução das } \\
\text { identidades }\end{array}$} & \multirow{2}{*}{$\begin{array}{l}\text { Imigrantes } \\
\text { brasileiros nos } \\
\text { EUA } \\
\text { Catalães, } \\
\text { Espanhóis e outros }\end{array}$} \\
\hline & & & Articulação & & \\
\hline
\end{tabular}

Fonte: Elaborado pelo autor (2017).

A primeira ocorrência à noção de interação na conferência proferida por Barth diz que "Ao terem experiências semelhantes e se engajarem mutuamente em reflexões, instruções e interações, as pessoas são induzidas a conceitualizar e, em parte, compartilhar vários modelos culturais" (BARTH, 2005, p. 17). Tal afirmação consta da introdução do seu discurso e aponta para a aprendizagem e alteridade como aspectos relacionados à indução e compartilhamento derivados das reflexões, 
instruções e interações que compõem as experiências culturais dos indivíduos. Em Arruti, o destaque dado às etnografias das interações e suas derivações (conforme evoquei anteriormente) indica, logo na introdução da conferência do autor, que o seu interesse se volta para "[...] a produção do outro pelos missionários, pelos nativos e, finalmente, pela antropologia [...]” (ARRUTI, 2004, p. 2). Segundo este autor, compreender os processos de conversão e produção da alteridade é um caminho para se compreender a interação entre os diversos agentes e as etnogêneses entre os Xocó. Por fim, encontraremos as enunciações do conceito de interação em Roberto Cardoso de Oliveira a partir da busca de definição daquilo que o autor chama de "[...] condições de possibilidades de etnização das identidades nacionais de imigrantes residentes em sociedades anfitriãs [...]" (OLIVEIRA, 2000, p. 8). Partindo desta indicação, o autor recorre ao termo interação em diferentes pontos de análise, por seis vezes (em dois parágrafos), até sugerir que:

[...] no mundo moderno, a observação desses grupos oferece uma oportunidade privilegiada para o estudo daquelas formas de interação onde a articulação entre a identidade, a etnicidade e a nacionalidade se impõe como um foco de inegável valor estratégico para uma investigação que se pretenda capaz de elucidar os mecanismos de identificação pelos outros, tanto quanto os de auto-identificação, não obstante esta ser reflexo daquela [...]. (OLIVEIRA, 2000, p. 8).

O destaque dado à articulação e à identificação oferece ao desdobramento conceitual da interação as ideias subjacentes de que aprender a se situar em uma determinada sociedade anfitriã supõe a busca de diferentes formas de construção de elementos identitários étnicos ou nacionais, nos quais se aprende a movimentar-se na casa dos outros.

As implicações teóricas entre os autores indicam que a transformação do Toré em código cultural, a distribuição da cultura a partir de experiências culturais e a tradução de identidades resultam das alternativas encontradas para o exercício de diferentes situações de aprendizagem e produção de alteridade no trânsito cultural por diferentes contextos e circunstâncias de convívio social. O Toré é um código que se dança (ou ritualiza-se para aprendê-lo em casa); aprender norueguês para um pathan é também uma forma de mover-se com os seus longe de casa; buscar a consideração dos outros numa sociedade anfitriã é pôr em movimento marcas de pertencimento nacional ou étnico evocativas do reconhecimento dos outros e nas casas dos outros.

Além de compartilharem suas simpatias teóricas nos corpos discursivos dos estudos de etnicidade, as conferências aqui analisadas oferecem elementos para a emergência de outras compreensões sobre os processos de aprendizagem. O esforço que fiz até aqui foi para indicar, nos traços de cada escrita, elementos convergentes para a produção de outras explorações teóricas dentro 
do discurso da antropologia de maneira a abrir caminho para um amplo diálogo com outras áreas das ciências humanas.

\section{Conclusões}

O título de apresentação deste ensaio enunciou as produções de si com(o) outro. Recorri à estratégia semelhante à de Roberto Cardoso de Oliveira para apresentar os (des)caminhos da identidade. Lancei mão de um recurso que inscreve ambivalência no interior de uma palavra, optei pela exploração da ambivalência no conectivo entre os termos do enunciado na primeira frase do título. Isto porque procuro sugerir que as ligações entre aprendizagem e alteridade, em determinadas formas de organização social, são portadoras de condições ambivalentes na produção de limites na geração de novas formas de tornar-se outro com os outros e consigo mesmo (compreendendo aqui que estar consigo é também uma forma de estar com os outros). As maneiras como ocorrem os trânsitos culturais variam conforme as ligações que pessoas e grupos estabelecem nos diferentes contextos de suas experiências culturais.

Inicialmente, destaquei aspectos referentes à antropologia e educação, a título de ressaltar a importância de uma conversação interdisciplinar que possa contribuir para a formação de educadores, envolvidos ou não, com questões de etnicidade na educação. Além de enfatizar as bases argumentativas que buscam situar relevâncias dos estudos sobre etnicidade dentro do debate especializado da antropologia, procurei lançar tais discursos a outros horizontes, com o firme propósito de fazer pensar fora da sentença, conforme sugere Homi Bhabha (1998). Penso que, no contexto brasileiro, como um todo, ainda existem barreiras epistemológicas, pedagógicas e políticas que obstruem canais de conversação entre a antropologia e educação (áreas de saber destacadas dentro dos limites deste ensaio) e que, além das diferentes formas de compreender a aprendizagem e a produção de alteridade nos domínios da antropologia, é possível entrever possibilidades de como tais conceitos resultam, também, nos processos de diferenciação que perpassam não apenas as relações sociais no trabalho com diferentes grupos étnicos, mas também as relações sociais em processos educacionais.

Optei em fazer uma análise de discurso de três conferências feitas por antropólogos e para antropólogos. Tomei como exemplo as análises de discurso que Clifford Geertz (com outros acréscimos) fez para relacionar obras, vidas e produção de diferentes gêneros discursivos entre importantes nomes da antropologia. Ao contrário de Geertz (2009), não destaquei as diferenças de 
gênero, mas as diferenças de assinaturas, temáticas e as configurações empíricas (as quais reapresentei de forma alegórica como situações do estar em casa, longe de casa e na casa dos outros). Ainda em contraposição a este antropólogo, a minha intenção não foi circunscrever a produção teórica dos estudos de etnicidade ao campo disciplinar da antropologia, procurei extrapolar as suas determinações epistemológicas, para compreender tais estudos como produtores de discursos sociais. Para apresentar os contrastes geopolíticos entre os discursos, os contextos são ressaltados como cenários de relações de poder que instauram determinadas formas de aprender e produzir alteridade. Posteriormente, apresentei um quadro geral de análise, no qual relaciono os agenciamentos de sentidos entre aprendizagem e produção de alteridade sob o traço firme e recorrente do conceito de interação.

Considero importante retornar a Tomaz Tadeu da Silva (2000) para dizer que fiz o que fiz por compreender que os estudos de etnicidade podem contribuir para a interlocução com outros campos de conhecimento, sobretudo no que diz respeito aos temas da identidade e da diferença. Faço coro às observações deste autor, quando ele afirma que:

A questão da identidade, da diferença e do outro é um problema social ao mesmo tempo em que é um problema pedagógico e curricular. É um problema social porque, em um mundo heterogêneo, o encontro com o outro, com o estranho, com o diferente, é inevitável. É um problema pedagógico e curricular não apenas porque as crianças e os jovens em uma sociedade atravessada pela diferença, forçosamente interagem com o outro no próprio espaço da escola, mas também porque a questão do outro e da diferença não pode deixar de ser matéria de preocupação pedagógica e curricular. (SILVA, 2000, p. 97).

Desta forma, recorri às páginas da antropologia em que circulam os discursos sobre a etnicidade na tentativa de descrever os modos de produção destes discursos e, ao mesmo tempo, reordená-los como discursos sociais a partir dos seus próprios termos, para averiguar possibilidades de novas interlocuções, indicando, aqui e ali, conexões possíveis com o debate contemporâneo sobre educação e apresentando alguns dos seus desdobramentos na formação de professores.

\section{REFERÊNCIAS}

APPLE, M. W. Política Cultural e Educação. São Paulo: Cortez, 2000.

ARRUTI, J. M. A produção da alteridade: o Toré como código das conversões missionárias e indígenas. In: ESTANQUE, E. et al. A questão social do novo milênio. Coimbra: Centro de Estudos Sociais, 2004.

ARRUTI, J. M. Mocambo: antropologia e história no processo de formação quilombola. Bauru, SP: EDUSC, 2006. 
BARTH, F. Etnicidade e o conceito de cultura. Tradução: Paulo Gabriel Hilu da Rocha Pinto. Antropolítica, n. 19, p. 15-30. Niterói, RJ: UFF, 2005.

BARTH, F. O guru, o iniciador e outras variações antropológicas. Tradução: John Cunha Comerfort. Rio de Janeiro: Contra Capa, 2000.

BHABHA, H. K. O local da cultura. Tradução: Myriam Ávila, Eliana Lourenço de Lima Reis e Gláucia Renata Gonçalves. Belo Horizonte: UFMG, 1998.

BRANDÃO, A.; SILVA, A. P. Raça e Educação: os elos nas Ciências Sociais Brasileiras. In: PINHO, O.; SANSONE, L. Raça: novas perspectivas antropológicas. Salvador, BA: Associação Brasileira de Antropologia: EDUFBA, 2008.

CAIAFA, J. Aventura das Cidades. Rio de Janeiro: FGV, 2007.

CANDAU, V. M.; MOREIRA, A. F. Multiculturalismo: diferenças culturais e práticas pedagógicas. Petrópolis, RJ: Vozes, 2011.

COHN, C. Antropologia da Criança. Rio de Janeiro: Jorge Zahar, 2009.

DAUSTER, T. Escrever: formação e identidade num universo de escritoras. In: DAUSTER, T.; TOSTA, S. P.; ROCHA, G. Etnografia e Educação. Rio de Janeiro: Lamparina, 2012.

ERIKSEN, T. H.; NIELSEN, F. S. História da Antropologia. Tradução: Euclides Luiz Calloni. Petrópolis: Vozes, 2010.

FOUCAULT, M. O que é um autor? Tradução: José A. Bragança de Miranda e Antonio Fernando Cascais. Lisboa: Passagens, 2006.

FREITAS, M. C. Alunos Rústicos, Arcaicos e Primitivos: o pensamento social no campo da educação. São Paulo: Cortez Editora, 2005.

GEERTZ, C. Obras e Vidas: o antropólogo como autor. Tradução: Vera Ribeiro. Rio de Janeiro: Editora UFRJ, 2009.

GRÜNEWALD, R. A. (org.). Toré: regime do encantado. Recife: Fundação Joaquim Nabuco, 2005.

MCLAREN, P. Rituais na Escola: em direção a uma economia política de símbolos e gestos na educação. Petrópolis: Vozes, 1992.

. Multiculturalismo Crítico. São Paulo: Cortez, 2000.

OLIVEIRA, A. Antropologia e Antropólogos, Educação e Educadores: o lugar do ensino de Antropologia na formação docente. Revista Percursos, v. 13, n. 1, p. 120-132. Florianópolis: EDUFSC, 2012.

OLIVEIRA, R. C. Os (des)caminhos da identidade. Revista Brasileira de Ciências Sociais, v. 15, n. 42, p. 7-21, São Paulo: Anpocs, 2000. 
OLIVEIRA, R. C. Os diários e suas margens. Brasília: UnB, 2002.

ORGANIZAÇÃO DAS NAÇÕES UNIDAS PARA A EDUCAÇÃO, CIÊNCIA E CULTURA (UNESCO). Educação, um Tesouro a Descobrir: Relatório para a UNESCO da Comissão Internacional sobre Educação para o Século XXI. São Paulo: Cortez; Brasília: MEC/UNESCO, 2001.

PRATT, M. L. Os Olhos do Império: relatos de viagem e transculturação. Tradução: Jézio Hernani Bonfim Gutierre. Bauru, SP: EDUSC, 1999.

RIBEIRO, D. Os índios e a civilização: a integração das populações indígenas no Brasil moderno. São Paulo: Companhia das Letras, 1996.

ROCHA, G.; TOSTA, S. Antropologia \& Educação. Belo Horizonte: Autêntica, 2009.

SILVA, T. T. A Produção Social da Identidade e da Diferença. In: Identidade e Diferença: a perspectiva dos estudos culturais. Petrópolis, RJ: Vozes, 2000. p. 73-102.

VIEIRA JÚNIOR, R. J. Rumo ao Multiculturalismo: a adoção compulsória de ações afirmativas pelo Estado brasileiro como reparação dos danos atuais sofridos pela população negra. In: SANTOS, S. A. (Org.). Ações Afirmativas e Combate ao Racismo nas Américas. Brasília: Ministério da Educação, Secretaria de Educação Continuada, Alfabetização e Diversidade, 2005. p. 83-101. Coleção educação pra todos.

WALKERDINE, V. O raciocínio em tempos pós-modernos. Revista Educação e Realidade, v. 20, n. 2, p. 207-226. Tradução: Tomaz Tadeu da Silva. Porto Alegre: EdUFRGS, 1995. 
Productions of the Self with the Other: Learning and production of otherness

\begin{abstract}
This essay aims to highlight the importance of conversations between anthropology and education, giving special emphasis to the concepts of learning and production of otherness. It is a theoretical study, which uses discourse analysis of three lectures by anthropologists who study ethnicity. The objective is to present how theoretical literature on ethnicity produces other forms of understanding and of otherness. It highlights the importance of learning in different circumstances of intercultural encounters and thus make deeper reflections on multicultural approaches to teacher education.
\end{abstract}

Key words: Anthropology. Teachers' education and ethnicity.

\section{Álamo Pimentel}

E-mail: alamopimentelmcz@gmail.com
Las producciones de sí con (el) otro: aprendizaje y producción de alteridad

\section{Resumen}

En el presente ensayo intentamos destacar la importancia del diálogo existente entre la antropología y la educación. El énfasis del trabajo está puesto esencialmente em las nociones de aprendizaje y producción de alteridad. Se trata de un estudio teórico sobre el análisis del discurso de tres conferencias de antropólogos investigadores del tema etnicidad. Nuestro objetivo es dar a conocer cómo la producción teórica sobre etnicidad es también productora de otras formas de comprensión tanto del aprendizaje como de la alteridad. Procuramos también destacar la importancia del aprendizaje en diferentes circunstancias de encuentros interculturales y, con ello, plantear reflexiones más profundas sobre los enfoques multiculturales de los procesos educativos en la formación de profesores.

Palabras clave: Antropología. Formación de profesores y etnicidad.

Enviado em: 27/05/2015

Versão final recebida em: 19/10/2016

Aprovado em: 06/11/2016 